\title{
Neuropsychiatric symptoms and faster progression of cognitive impairments as predictors of risk of conversion of mild cognitive impairment to dementia
}

\author{
Mariola Bidzan¹, Leszek Bidzan², Ilona Bidzan-Bluma1,3
}

\author{
1Department of Clinical Psychology and Neuropsychology, Institute of Psychology, \\ University of Gdansk, Gdansk, Poland \\ 2Department of Developmental Psychiatry, Psychotic Disorders and Old Age \\ Psychiatry, Medical University of Gdansk, Gdansk, Poland \\ ${ }^{3}$ Neuropsychological Diagnostic and Therapy Centre, Gdansk, Poland
}

Submitted: 28 January 2017

Accepted: 24 March 2017

Arch Med Sci 2017; 13, 5: 1168-1177

DOI: https://doi.org/10.5114/aoms.2017.68943

Copyright $\odot 2017$ Termedia \& Banach

\begin{abstract}
Introduction: The aim of this research, based on 7 years of observations, was to assess the relationship between the dynamics of changes in the realm of cognitive functions in the early stages of observations and the presence of neuropsychiatric symptoms as well as further progression of cognitive function impairments in people diagnosed with mild cognitive impairment $(\mathrm{MCl})$.

Material and methods: One hundred and ninety three individuals were included in the study, all of whom referred themselves to the Mental Health Clinic and were diagnosed with $\mathrm{MCl}$ based on the criteria of the Working Group on $\mathrm{MCl}$. It was assumed that these individuals would be subjected to systematic psychiatric and neuropsychological observation until they were diagnosed with dementia. This report concerns a completed 7-year period of these observations. Participants were assessed based on the following scales: MMSE, NPI and GDS.

Results: The obtained results indicate statistically significant differences between groups of subjects at the time of inclusion in the study, regarding the frequency of occurrence and severity of the following categories of impairments: thought impairments $(p<0.001)$, arousal/aggression $(p<0.001)$, depression/dysphoria $(p<0.001)$, disinhibition $(p<0.03)$, irritability/lability $(p<0.001)$, abnormal motor behaviors $(p<0.02)$, as well as sleep and night-time behavior disorders $(p<0.01)$ Moreover, individuals who developed dementia during observation exhibited greater progression in cognitive function impairment assessed with the MMSE scale in the first year of observation $(p<0.01)$.

Conclusions: The accruing of cognitive function impairments and the presence of neuropsychiatric symptoms seem to be important risk factors for the development of dementia.
\end{abstract}

Key words: dementia, neuropsychology, mild cognitive impairment, cognitive impairments, neuropsychiatry.

\section{Introduction}

Among the conditions associated with the decrease of cognitive abilities during the ageing process, mild cognitive impairment $(\mathrm{MCl})$ is of particular interest. Mild cognitive impairment is considered to be a risk

\author{
Corresponding author: \\ Prof. Mariola Bidzan PhD \\ Department of Clinical \\ Psychology and \\ Neuropsychology \\ Institute of Psychology \\ University of Gdansk \\ 4 Bażyńskiego St \\ 80-952 Gdansk, Poland \\ Phone/fax: +48 602316161 \\ E-mail: mariola.bidzan@ \\ ug.edu.pl
}


factor for different types of dementia, including Alzheimer's [1, 2].

Some studies suggest that $50 \%$ of individuals diagnosed with $\mathrm{MCl}$ will develop fully symptomatic dementia within 3-4 years. On the other hand, a large proportion of people diagnosed with $\mathrm{MCl}$ will not undergo further cognitive function impairment [3].

Another difficulty in researching $\mathrm{MCl}$ is the lack of precise criteria for this category of impairments [4, 5]. Despite significant recent advances, the boundaries of this category are not well defined [5-7].

This problem with outlining strict diagnostic criteria means that conditions which differ in terms of their pathogenesis, including initial states of dementia, may function under the term $\mathrm{MCl}$. From a practical point of view, the prognosis of the further course of cognitive impairments is of key importance.

A number of studies have attempted to identify factors indicating a heightened risk of conversion of $\mathrm{MCl}$ into dementia, but their results are inconclusive [8].

At first it seemed that the distinction between forms of $\mathrm{MCl}$, such as affecting one or many areas of cognitive functioning, as well as with or without memory impairment, would have a significant predictive value [7, 9].

For instance, the highest risk of conversion to Alzheimer's was believed to concern individuals with memory impairments, particularly episodic memory impairments, which are not associated with other cognitive dysfunctions [10].

On the other hand, the lack of clear confirmation of a relationship between specific forms of $\mathrm{MCl}$ and their subsequent course needs to be emphasized [8].

One could infer from studies concerned not only with $\mathrm{MCl}$, but also with clinical forms of dementia, that neuropsychiatric disorders are associated with faster progression of cognitive impairments. In some reports one can come across the view that the presence of neuropsychiatric symptoms (such as mood disorders, psychotic symptoms, aggressive and impulsive behavior, sleep disorders, etc.) accelerates the process of conversion of $\mathrm{MCl}$ to dementia [11, 12].

The aim of this study was to assess the relationship between the dynamics of changes in the realm of cognitive functions in the initial period of observation as well as the presence of neuropsychiatric symptoms and further progression of cognitive function impairment, based on 7-year-long prospective research on people diagnosed with $\mathrm{MCl}$.

\section{Material and methods}

The population the sample was drawn from people who referred themselves to the Mental Health Clinic in the years 2005-2007.
It was assumed that these individuals would undergo systematic psychiatric observation until they were diagnosed with dementia. This report deals with a completed period of 7 years of observation.

The participants were selected based on the following criteria:

Inclusion criteria:

- Consent to participate in the study;

- Diagnosis of $\mathrm{MCl}$ based on the criteria of the Working Group on Mild Cognitive Impairment [9], which assume:

- visible decline in cognitive functions as self-assessed by the participant or based on information from a caregiver, as well as objective confirmation (through examination) of cognitive impairment and/or visible decline in cognitive function over time (based on an objective examination),

- a continued capability to perform basic everyday activities with minimal impairment in performing complex activities;

- No psychiatric pharmacotherapy at the time of inclusion;

- The presence of a person from the participant's social environment who lives with the participant, or at least visits the participant a few days a week, who expresses readiness to take part in the study as an informant (required for assessments of some of the clinical scales used);

- Level 3 (mild cognitive decline) on the Reisberg et al. Global Deterioration scale [4];

- A score of 24-30 points on the Mini Mental State Examination [13] scale.

Exclusion criteria:

- A diagnosis of dementia, regardless of its etiology;

- Exclusion of dementia;

- Mini Mental State Examination Scale score below 24 points;

- A history of any of the following conditions: affective disorder, schizophrenia, alcoholism, drug addiction, epilepsy, Parkinson's disease, intellectual disability;

- Any of the following present at the time of examination: consciousness disorders, motor, visual, or auditory system impairments that would significantly hinder the completion of the tasks and procedures for the clinical scales; other serious somatic conditions, particularly those in the decompensation phase;

- Refusal to take part in the study at any time during the observations.

Patients with diagnosed $\mathrm{MCl}$ were not administered any pharmacological treatment due to the lack of any registered pharmacological drugs for $\mathrm{MCl}$. Pharmacological treatment (acetylcholines- 
terase inhibitors) was administered in the case of some of the patients, but only once the dementia symptoms were observed. No specialist non-biological techniques were applied either, except for having conversations with the patients, which were to motivate them to take up more intellectual, physical and social activities. Such conversations were held with each of the patients whenever we had any contact with them.

The study was conducted in accordance with the Declaration of Helsinki and was approved by the local Ethics Committee (Medical University, Gdansk, Poland).

One hundred and ninety-three individuals were included in the study.

All the qualified individuals were examined. This involved:

An assessment of cognitive functions based on the score on the Mini Mental State Examination scale, which ranges from 0 (severe dementia) to 30 (no cognitive function impairment) [13]. Taking into account the influence that age and education may have on the MMSE, the obtained raw scores were re-calculated correcting for age and education level using the formula proposed by Mungas et al. [14], adapted for use in Poland by Jóźwiak et al. [15]. Corrected scores were used for the statistical analyses (MMSE-C).

An assessment of the presence of psychiatric symptoms was done with the help of the Neuropsychiatric Inventory (NPI), developed by Cummings et al. [16]. The version of the inventory used in the current study contains an assessment of 12 categories (listed in Table I). For each category of impairments, an assessment is made in terms of frequency on a 4-point scale (1 - sporadically, 4 - very often) and of severity of impairments on a 3 -point scale ( 1 - mild, 3 - severe). Some ver- sions of this scale also contain an assessment of the influence of the observed impairments on the social environment (distress), which was not analyzed in this study.

Another scale used was the Geriatric Depression Scale (GDS), constructed by Yesavage et al., the full version of which (used in this study) contains 30 self-assessed questions, but it is also possible to complete the questionnaire based on information provided by the caregiver (observer-rated) [17]. The self-assessed version was used for this research, but it was checked against the opinion of the caregiver and if there were significant discrepancies the subject was re-examined. In the full version of the scale it is assumed that scoring above 11 corresponds to mild depression and over 21 to severe depression.

The assessment of cognitive functions using the MMSE scale was repeated after a year on average (between 9 and 13 months) after inclusion in the study. Another assessment on the MMSE scale took place at the end of observation, i.e. either at the time of being diagnosed with dementia, or 7 years after inclusion in the study.

Due to the fact that the individuals under observation remained under the direct care of the authors of the current study, their psychological condition was systematically monitored several times a year on average.

The clinical diagnosis was verified at each successive consultation, especially when diagnosing or ruling out dementia. If dementia was diagnosed, further examinations were conducted, including laboratory and radiology examination, in order to assess the etiology of the process. The examinations were guided by the DSM-IV-TR criteria, which were in place at the time when the study was initiated [18].

Table I. Mean scores of the studied outpatients $(n=75)$ diagnosed with $\mathrm{MCl}$ at the time of inclusion in the study

\begin{tabular}{|lcccc|}
\hline Parameter & Mean & Minimum & Maximum & SD \\
\hline Age & 77.13 & 57.00 & 96.00 & 4.18 \\
\hline Education & 10.97 & 1.00 & 17.00 & 2.96 \\
\hline MMSE-IC & 27.34 & 21.55 & 33.50 & 3.17 \\
\hline MMSE-IIC & 25.59 & 18.51 & 31.80 & 2.21 \\
\hline MMSE-I-IIC & 1.75 & -4.00 & 6.00 & 5.45 \\
\hline MMSE-VIIC & 22.92 & 5.00 & 25.00 & 5.24 \\
\hline GDS & 11.15 & 0.00 & 81.00 & 20.84 \\
\hline NPI-Total & 27.88 & 5.00 & 25 & 24 \\
\hline
\end{tabular}

MMSE-C - mean scores on the MMSE scale with the Mungas et al. correction; MMSE-IC - mean scores at the first examination, i.e. at the time of inclusion in the study; MMSE-IIC - at the second examination, i.e. after an average of 1 year; MMSE-I-IIC - the difference in the MMSE scores between the first and second examinations; MMSE-VIIC - mean scores at the end of observation, i.e. when dementia is diagnosed or 7 years after the initiation of observation; GDS - mean results on the GDS scale at the time of inclusion in the study; NPI mean results on the NPI scale at the time of inclusion in the study. 


\section{Statistical analysis}

A two-tailed independent $t$-test was used to compare the means. A $p$-value of $\leq 0.05$ was taken as the threshold of statistical significance. The assumptions of normality were tested using the $\chi^{2}$ test, and the assumptions of equal variance using the $F$-test.

\section{Results}

Of the 193 individuals included in the study, 75 were included in the final analyses, based on either concluding the 7-year period of observation or developing dementia during the observation (independent of the time since the beginning of the observation).

Thirty-four subjects developed dementia during the observation period, of which 16 developed Alzheimer's type dementia, 4 developed vascular dementia, 2 developed Lewy body dementia, and 3 developed fronto-temporal dementia. For the remaining 9 individuals either there were no data allowing the identification of the etiology of dementia at the time of preparation of this report, or the dementia was assessed as having mixed etiology. The types of dementia were not subject to further analysis, both because of the sample size being too small and taking into account the fact that there was a relatively large group where a final diagnosis in terms of etiology was not made.

Based on the final clinical diagnosis in which dementia was either confirmed or ruled out, the subjects were divided into two groups:

- subjects with $\mathrm{MCl}$ who converted to dementia during the 7-year observation period ( $\mathrm{MCl}-\mathrm{D}$, $n=34$ ) (subjects with dementia);

- subjects with $\mathrm{MCl}$ among whom there was no basis for diagnosing dementia during the 7-year observation period ( $\mathrm{MCl}-\mathrm{nD}, n=41)$ (subjects who did not develop $\mathrm{MCl}$ after 7 years)

Education was taken into account when calculating the MMSE result, where Mungas's algorithm, which includes both education and age, was used (as presented in Table I).

Patients with dementia (MCl-D) had on average 9 years of education, and patients from the group without $\mathrm{MCl}-\mathrm{nD}$ had 12 years of education. This result is statistically significant $(t=2.299, p=0.024)$.

The mean scores of subjects included in the analyses $(n=75)$ are presented in Table I. The mean scores on the MMSE scale (with the Mungas et al. correction - MMSE-C), at the first examination, i.e. at the time of inclusion in the study (MMSE-IC), at the second examination, i.e. after an average of one year (MMSE-IIC), the difference in MMSE scores between the first and the second examination (MMSE-I-IIC) as well as at the end of observation, i.e. when dementia is diagnosed or seven years after the initiation of observation (MMSE-VIIC). Also presented are the mean results on the GDS and NPI scales at the time of inclusion in the study.

The mean values of the analyzed variables in the group of subjects with stable condition and the group of subjects in whom $\mathrm{MCl}$ converted into dementia (independent of its etiology) are presented in Table II. While there are no statistically significant differences in terms of age and the baseline levels of cognitive functions assessed on the MMSE scale, all of the other presented values differ significantly.

The NPI scale was used to measure the presence and severity of psychopathological symptoms at the time of inclusion of people diagnosed with $\mathrm{MCl}$. Table III presents the results of the separate psychopathological categories on the scale.

The two groups ( $\mathrm{MCl}-\mathrm{D}$ and $\mathrm{MCl}-\mathrm{nD}$ ) differed in terms of both severity and frequency of the occur-

Table II. Comparison of age, scores on the MMSE scale, as well as the global score and the scores in separate categories in scales assessing the activity during the baseline examination in individuals affected by $\mathrm{MCl}$ who converted to dementia (MCl-D) and in those whose condition is stable ( $\mathrm{MCl}-\mathrm{nD})$

\begin{tabular}{|c|c|c|c|c|c|c|c|c|c|}
\hline Variable & $\begin{array}{l}\text { Mean } \\
\text { MCI-D } \\
n=34\end{array}$ & $\begin{array}{c}\text { Mean } \\
\text { MCl-nD } \\
n=41\end{array}$ & $t$ & $\mathrm{~d} f$ & $P$-value & $\begin{array}{c}\text { MCl-D } \\
\text { SD }\end{array}$ & $\begin{array}{c}\mathrm{MCl}-\mathrm{nD} \\
\mathrm{SD}\end{array}$ & $\begin{array}{c}F-\text { vari- } \\
\text { ances }\end{array}$ & $\begin{array}{c}P \text { - vari- } \\
\text { ances }\end{array}$ \\
\hline Age & 78.79 & 75.76 & 1.44 & 73 & 0.16 & 8.40 & 9.67 & 1.33 & 0.41 \\
\hline MMSE-IC & 27.20 & 27.45 & -0.36 & 73 & 0.72 & 3.08 & 2.89 & 1.13 & 0.70 \\
\hline MMSE-IIC* & 24.70 & 26.33 & -2.28 & 73 & 0.03 & 3.37 & 2.83 & 1.42 & 0.29 \\
\hline MMSE I-IIC* & 2.50 & 1.12 & 2.82 & 73 & 0.01 & 2.03 & 2.17 & 1.14 & 0.71 \\
\hline MMSE VIIC* & 19.14 & 26.06 & -7.05 & 73 & $<0.001$ & 5.40 & 2.93 & 3.39 & $<0.001$ \\
\hline $\mathrm{GDS}^{\star}$ & 12.97 & 9.63 & 2.88 & 73 & 0.01 & 5.30 & 4.73 & 1.25 & 0.49 \\
\hline NPI-Total* & 41.62 & 16.49 & 6.48 & 73 & $<0.001$ & 19.83 & 13.63 & 2.12 & 0.02 \\
\hline
\end{tabular}


Table III. Comparison of scores in separate psychopathology categories of the NPI scale and the frequency and severity of symptoms in the group of subjects who converted to dementia (MCl-D) and those with a stable course $(\mathrm{MCl}-\mathrm{nD})$

\begin{tabular}{|c|c|c|c|c|c|c|c|c|c|}
\hline Parameter & $\begin{array}{l}\text { Mean } \\
\text { MCI-D } \\
n=34\end{array}$ & $\begin{array}{c}\text { Mean } \\
\mathrm{MCl}-\mathrm{nD} \\
n=41\end{array}$ & $t$ & $\mathrm{~d} f$ & $P$-value & $\begin{array}{c}\mathrm{MCl}-\mathrm{D} \\
\mathrm{SD}\end{array}$ & $\begin{array}{c}\mathrm{MCl}-\mathrm{nD} \\
\mathrm{SD}\end{array}$ & $\begin{array}{c}F-\text { vari- } \\
\text { ances }\end{array}$ & $\begin{array}{c}P \text { - vari- } \\
\text { ances }\end{array}$ \\
\hline Age & 78.79 & 75.76 & 1.44 & 73 & 0.16 & 8.40 & 9.67 & 1.33 & 0.41 \\
\hline \multicolumn{10}{|l|}{ Delusions: } \\
\hline Frequency ${ }^{\star}$ & 1.24 & 0.22 & 4.06 & 73 & $<0.001$ & 1.46 & 0.61 & 5.66 & $<0.001$ \\
\hline Severity* & 0.82 & 0.17 & 3.86 & 73 & $<0.001$ & 0.97 & 0.44 & 4.81 & $<0.001$ \\
\hline $\begin{array}{l}\text { Frequency x } \\
\text { severity* }^{*}\end{array}$ & 2.38 & 0.29 & 4.30 & 73 & $<0.001$ & 2.91 & 1.01 & 8.38 & $<0.001$ \\
\hline \multicolumn{10}{|l|}{ Hallucinations: } \\
\hline Frequency & 0.44 & 0.15 & 1.77 & 73 & 0.08 & 0.99 & 0.36 & 7.66 & $<0.001$ \\
\hline Severity & 0.32 & 0.15 & 1.44 & 73 & 0.15 & 0.68 & 0.36 & 3.65 & $<0.001$ \\
\hline $\begin{array}{l}\text { Frequency × } \\
\text { severity* }^{\star}\end{array}$ & 0.79 & 0.15 & 2.09 & 73 & 0.04 & 1.95 & 0.36 & 29.71 & $<0.001$ \\
\hline \multicolumn{10}{|l|}{$\begin{array}{l}\text { Agitation/ } \\
\text { aggression: }\end{array}$} \\
\hline Frequency* & 1.47 & 0.41 & 4.77 & 73 & $<0.001$ & 1.02 & 0.89 & 1.31 & 0.42 \\
\hline Severity* & 1.32 & 0.22 & 7.37 & 73 & $<0.001$ & 0.81 & 0.47 & 2.88 & $<0.001$ \\
\hline $\begin{array}{l}\text { Frequency } \\
\text { severity }^{*}\end{array}$ & 2.38 & 0.46 & 5.73 & 73 & $<0.001$ & 1.83 & 1.03 & 3.16 & $<0.001$ \\
\hline \multicolumn{10}{|c|}{ Depression/dysphoria: } \\
\hline Frequency* & 1.35 & 0.51 & 4.29 & 73 & $<0.001$ & 0.92 & 0.78 & 1.39 & 0.32 \\
\hline Severity* & 1.38 & 0.39 & 5.18 & 73 & $<0.001$ & 1.04 & 0.59 & 3.17 & $<0.001$ \\
\hline $\begin{array}{l}\text { Frequency x } \\
\text { severity }^{\star}\end{array}$ & 2.71 & 0.61 & 5.56 & 73 & $<0.001$ & 2.13 & 1.05 & 4.13 & $<0.001$ \\
\hline \multicolumn{10}{|l|}{ Anxiety: } \\
\hline Frequency* & 1.29 & 1.05 & 1.24 & 73 & 0.22 & 0.72 & 0.95 & 1.74 & 0.11 \\
\hline Severity* & 1.26 & 0.66 & 4.09 & 73 & $<0.001$ & 0.71 & 0.57 & 1.52 & 0.20 \\
\hline $\begin{array}{l}\text { Frequency × } \\
\text { severity* }^{*}\end{array}$ & 1.85 & 1.17 & 2.42 & 73 & 0.02 & 1.16 & 1.26 & 1.19 & 0.61 \\
\hline \multicolumn{10}{|c|}{ Elation/euphoria: } \\
\hline Frequency & 0.56 & 0.39 & 1.01 & 73 & 0.32 & 0.79 & 0.67 & 1.39 & 0.32 \\
\hline Severity & 0.50 & 0.37 & 0.87 & 73 & 0.39 & 0.71 & 0.62 & 1.29 & 0.44 \\
\hline $\begin{array}{l}\text { Frequency } \times \\
\text { severity }\end{array}$ & 0.71 & 0.51 & 0.82 & 73 & 0.41 & 1.03 & 1.00 & 1.06 & 0.86 \\
\hline \multicolumn{10}{|c|}{ Apathy/indifference: } \\
\hline Frequency & 1.26 & 1.10 & 0.60 & 73 & 0.55 & 1.21 & 1.20 & 1.02 & 0.94 \\
\hline Severity & 0.97 & 0.71 & 1.20 & 73 & 0.23 & 1.06 & 0.84 & 1.57 & 0.17 \\
\hline $\begin{array}{l}\text { Frequency } \times \\
\text { severity }\end{array}$ & 2.38 & 1.71 & 1.06 & 73 & 0.29 & 3.19 & 2.34 & 1.86 & 0.06 \\
\hline \multicolumn{10}{|l|}{ Disinhibition: } \\
\hline Frequency* & 0.56 & 0.27 & 2.17 & 73 & 0.03 & 0.61 & 0.55 & 1.25 & 0.50 \\
\hline Severity ${ }^{\star}$ & 0.76 & 0.22 & 3.60 & 73 & $<0.001$ & 0.85 & 0.42 & 4.16 & $<0.001$ \\
\hline $\begin{array}{l}\text { Frequency } \times \\
\text { severity* }^{*}\end{array}$ & 0.82 & 0.27 & 3.28 & 73 & $<0.001$ & 0.90 & 0.55 & 2.71 & $<0.001$ \\
\hline \multicolumn{10}{|c|}{ Irritability/lability: } \\
\hline Frequency* & 1.56 & 0.63 & 3.86 & 73 & $<0.001$ & 1.11 & 0.97 & 1.30 & 0.42 \\
\hline Severity* & 1.35 & 0.49 & 4.80 & 73 & $<0.001$ & 0.81 & 0.75 & 1.19 & 0.60 \\
\hline $\begin{array}{l}\text { Frequency × } \\
\text { severity }^{*}\end{array}$ & 2.56 & 0.95 & 3.94 & 73 & $<0.001$ & 1.93 & 1.61 & 1.43 & 0.28 \\
\hline
\end{tabular}


Table III. Cont.

\begin{tabular}{|c|c|c|c|c|c|c|c|c|c|}
\hline Parameter & $\begin{array}{l}\text { Mean } \\
\text { MCI-D } \\
n=34\end{array}$ & $\begin{array}{c}\text { Mean } \\
\text { MCI-nD } \\
n=41\end{array}$ & $t$ & $\mathrm{~d} f$ & $P$-value & $\begin{array}{l}\text { MCI-D } \\
\text { SD }\end{array}$ & $\begin{array}{l}\mathrm{MCl}-\mathrm{nD} \\
\mathrm{SD}\end{array}$ & $\begin{array}{c}F-\text { vari- } \\
\text { ances }\end{array}$ & $\begin{array}{c}P \text { - vari- } \\
\text { ances }\end{array}$ \\
\hline \multicolumn{10}{|c|}{ Motor disturbance: } \\
\hline Frequency ${ }^{\star}$ & 0.88 & 0.37 & 2.48 & 73 & 0.02 & 1.01 & 0.80 & 1.59 & 0.16 \\
\hline Severity* & 0.76 & 0.34 & 2.22 & 73 & 0.03 & 0.92 & 0.73 & 1.61 & 0.15 \\
\hline $\begin{array}{l}\text { Frequency × } \\
\text { severity* }\end{array}$ & 1.53 & 0.68 & 2.14 & 73 & 0.04 & 1.85 & 1.57 & 1.38 & 0.33 \\
\hline \multicolumn{10}{|c|}{ Night-time behaviors: } \\
\hline Frequency* & 0.94 & 0.29 & 2.77 & 73 & 0.01 & 1.23 & 0.78 & 2.47 & 0.01 \\
\hline Severity* & 0.68 & 0.20 & 2.88 & 73 & 0.01 & 0.91 & 0.51 & 3.19 & $<0.001$ \\
\hline $\begin{array}{l}\text { Frequency × } \\
\text { severity* }\end{array}$ & 1.62 & 0.39 & 3.08 & 73 & $<0.001$ & 2.27 & 1.07 & 4.50 & $<0.001$ \\
\hline \multicolumn{10}{|c|}{ Appetite/eating: } \\
\hline Frequency & 0.06 & 0.00 & 1.58 & 73 & 0.12 & 0.24 & 0.00 & 0.00 & 1.00 \\
\hline Severity & 0.06 & 0.00 & 1.58 & 73 & 0.12 & 0.24 & 0.00 & 0.00 & 1.00 \\
\hline $\begin{array}{l}\text { Frequency } x \\
\text { severity }\end{array}$ & 0.06 & 0.00 & 1.58 & 73 & 0.12 & 0.24 & 0.00 & 0.00 & 1.00 \\
\hline NPI-Total* & 41.62 & 16.49 & 6.48 & 73 & $<0.001$ & 19.83 & 13.63 & 2.12 & 0.02 \\
\hline
\end{tabular}

*Statistically significant differences $(p<0.05)$

Table IV. Comparison of age and score differences on the MMSE between the first and the second measurements (MMSE I-IIC) as well as the global score and scores on separate subscales of the NPI, and the GDS scores at baseline in groups of subjects with smaller (MMSE I-IIC-L) and larger (MMSE I-IIC-G) differences between the two subsequent MMSE measurements (MMSE I-IIC) (the threshold was set to the average score difference between the two measurements on the MMSE scale, i.e. MMSE I-IIC = 1.75)

\begin{tabular}{|c|c|c|c|c|c|c|c|c|c|}
\hline Variable & $\begin{array}{c}\text { MMSE } \\
\text { I-IIC-G } \\
n=42 \\
\text { Average }\end{array}$ & $\begin{array}{c}\text { MMSE } \\
\text { I-IIC-L } \\
n=33 \\
\text { Average }\end{array}$ & $t$ & $\mathrm{~d} f$ & $P$-value & $\begin{array}{c}\text { MMSE } \\
\text { I-IIC-W } \\
\text { SD }\end{array}$ & $\begin{array}{c}\text { MMSE } \\
\text { I-IIC-M } \\
\text { SD }\end{array}$ & $\begin{array}{c}F \text {-vari- } \\
\text { ances }\end{array}$ & $\begin{array}{c}P \text { - vari- } \\
\text { ances }\end{array}$ \\
\hline Age & 76.86 & 77.48 & -0.29 & 73 & 0.77 & 7.83 & 10.78 & 1.90 & 0.05 \\
\hline MMSE-IC* & 28.26 & 26.17 & 3.22 & 73 & $<0.001$ & 2.95 & 2.58 & 1.31 & 0.43 \\
\hline MMSE-IIC & 24.97 & 26.38 & -1.94 & 73 & 0.06 & 3.32 & 2.81 & 1.39 & 0.33 \\
\hline MMSE I-IIC* & 3.29 & -0.21 & 11.09 & 73 & $<0.001$ & 1.29 & 1.43 & 1.22 & 0.54 \\
\hline MMSE-VIIC & 22.33 & 23.68 & -1.07 & 73 & 0.29 & 5.69 & 5.11 & 1.24 & 0.54 \\
\hline GDS* $^{*}$ & 12.29 & 9.70 & 2.18 & 73 & 0.03 & 5.55 & 4.48 & 1.54 & 0.21 \\
\hline NPI-Total* & 33.95 & 20.15 & 3.00 & 73 & $<0.001$ & 22.04 & 16.50 & 1.78 & 0.09 \\
\hline
\end{tabular}

*Statistically significant differences $(p<0.05)$

rence of neuropsychiatric symptoms. Severity, frequency and burdensome (defined as frequency $x$ severity) of the neuropsychiatric symptoms, which were measured at the time of the patients' assignment to the study, were all greater in the case of patients with diagnosed dementia.

In Table IV, the global scores on the NPI and GDS scales are compared, depending on the level of changes in the assessment of cognitive functions at baseline and during the examination after a period of about 1 year.

Individuals with greater progression of cognitive disorders during the first year of observation were at the same time characterized by higher in-
Table V. Frequency of occurrence of dementia in groups with greater progression (MMSE I-IIC-G) and lesser progression (MMSE I-IIC-L) assessed on the basis of the MMSE score difference between baseline examination and examination after about a year of observation

\begin{tabular}{|lccc|}
\hline Course & MMSE I-IIC-G & MMSE I-IIC-L & Total \\
\hline MCI-nD & 20 & 21 & 41 \\
\hline MCl-D & 22 & 12 & 34 \\
\hline Total & 42 & 33 & 75 \\
\hline
\end{tabular}

$\chi^{2}=962, d f=74, p=0.001$ 
tensity of neuropsychiatric symptoms (the overall result of the NPI Scale).

A comparison was made between the numbers of subjects who were characterized by higher (above 1.7 patients) and lower frequencies of changes after a year of observations in groups of subjects in whom dementia was diagnosed or ruled out, taking into account the mean score difference between the baseline examination and the second examination (after about a year) on the MMSE scale. As can be seen from the results of the count analysis, they differ significantly (Table V).

\section{Discussion}

Not everyone who underwent conversion to dementia was also subject to visible (based on the MMSE examination) progression of cognitive impairments. Even ignoring the limitations of the method itself, one ought to see that the lack of this kind of progression can be explained by the very nature of the process of dementia. One ought to take into account that the level of progression of cognitive function impairment in Alzheimer's disease varies greatly between affected individuals and, equally importantly, the speed of the progression differs between stages of disease. It is assumed that in the initial periods of development of the condition, the levels of progression are small, speeding up during the course of the process $[19,20]$.

Independent of the above concerns, the assessment of the progression of cognitive function impairments seems to be one of the most important diagnostic elements, and it should be taken into account in the $\mathrm{MCl}$ diagnostic criteria.

Statistical analysis shows that the occurrence of neuropsychiatric symptoms at the beginning of the observation period differentiates individuals among whom dementia developed during the 7-year observation period (MCl-D) and those who did not exhibit significant progression of cognitive function impairments $(\mathrm{MCl}-\mathrm{nD})$. Differences are seen in both the global intensity of neuropsychiatric symptoms (global score on the NPI scale) and the separate subscales. Here, it is worth noting the observations that associate the increased frequency of the occurrence of neuropsychiatric symptoms with the initial stages of dementia [21].

Moreover, neuropsychiatric disorders are especially related to faster progression of cognitive impairments [11, 12]. It seems reasonable to state that an accelerated neurodegenerative process is responsible for the more frequent occurrence of a number of non-cognitive symptoms, such as (Table III): delusions, agitation/aggression, depression/dysphoria, disinhibition, irritability/lability, motor disturbance as well as sleep and night-time disorders.

Similar observations were made based on the results of previous studies $[11,12]$. The results of different studies differ in terms of particular categories of psychopathological symptoms, but they usually point to their more frequent occurrence among individuals who are soon to develop dementia [22]. Mood disorders preceding the deterioration of cognitive functions seem the most typical [23]. The more frequent occurrence and severity of mood disorders in the $\mathrm{MCl}-\mathrm{D}$ group, on both the NPI and the GDS scales, was also confirmed in this study (Tables II and III).

The concept of the chronic character of dementia conditions assumes the presence of a longterm pre-clinical phase in which the biological processes leading to brain lesions have already begun $[24,25]$. Clinical symptoms which occur in the period preceding the development of fully symptomatic dementia are usually associated with a gradual decline in cognitive functions. Impairment of immediate memory and the associated "distraction" often appear in the early stages of the disease and in periods preceding the disease [26]. Particular attention is given to the diagnostic importance of impairments in delayed recall [27]. The above symptoms are also considered to be typical of $\mathrm{MCl}$, which may give the impression that differentiation between the initial stages of Alzheimer's disease and $\mathrm{MCl}$ is practically impossible. A concern may even arise about whether it is justified at all to diagnose $\mathrm{MCl}$, understood as a separate diagnostic category, in an individual exhibiting even a small progression of cognitive impairments.

When selecting for inclusion in this study, more rigorous criteria diagnostic criteria for $\mathrm{MCl}$ were adopted, based on modern guidelines [9]. Observation of the group selected this way suggests that a gradual decline of cognitive functions is observed in most people with $\mathrm{MCl}$, but the nature of this decline varies between individuals. In some studies, where diagnosis of $\mathrm{MCl}$ was much less rigorous, a much larger (in comparison to the current study) group of people with a stable course of $\mathrm{MCl}$ was reported [28].

Despite significant efforts made in the past two years, the diagnostic criteria of this category are still not strictly defined. This leads to conditions of different etiopathogenetic causes qualifying as $\mathrm{MCl}$ [6]. Moreover, a significant number of individuals classified as having $\mathrm{MCl}$ actually have age-associated memory impairment (AAMI), which, though even here the opinions are not unanimous, is usually not associated with a clear progression leading to dementia, at least over a short period of time [29].

The remaining individuals, some of whom will exhibit the clinical form of dementia in the upcoming years, may be treated as individuals already undergoing the process of dementia. This 
is probably why risk factors for an unfavorable course of $\mathrm{MCl}$ (indicative of conversion) are effectively identical to those identified for the processes of dementia [30].

However, devoting attention to individuals who present small but objectively verifiable problems in terms of cognitive functions, independent of any doubts that may arise from defining the term $\mathrm{MCl}$ itself, is absolutely beneficial from the point of view of clinical practice. Regardless of the efficacy of future therapeutic methods on dementia, the time of initiation of therapy will always be of utmost importance (as will prophylaxis). The attention paid in the current study to the prognostic value of the initially faster decline of cognitive functions as well as the presence of neuropsychiatric symptoms may contribute to developing efficient algorithms for the treatment of individuals exhibiting so-called mild cognitive impairments.

The study was based on a generally approved tool for the quantification of neuropsychiatric symptoms (the NPI). The tool was constructed to assess psychopathological symptoms exhibited in the course of processes associated with brain lesions [16, 31].

Taking into account the frequently heightened presence of mood disorders and their relationship with the progression of cognitive function impairments, the Geriatric Depression Scale (GDS) was also used in the study. The scale uses self-reports from the subject or the reports of their caregiver, and it is more suited than other tools for measuring depression in older subjects [17].

In turn, the assessment of cognitive functions was done using the MMSE scale, which allows the estimation of cognitive function impairments. While it is not a tool suitable for the precise measurement of the severity of levels of cognitive dysfunctions, it is widely used in practice because of the simplicity and quickness of the examination procedure.

Because the MMSE scale scores depend on education and age, the algorithm of Mungas et al. was used in the interpretation of results [14]. It seems that the results indicate the usefulness of the MMSE scales in making prognoses about the subsequent course of $\mathrm{MCl}$. As can be seen in Table II, the comparison of results on the MMSE scale at the time of inclusion in the study and after a period of about one year may be an important prognostic cue. Greater progression of disorders is associated with decidedly worse subsequent course (Table V). This is not a new observation. Almost 10 years ago the authors concluded that the assessment of the dynamics of the potential progression of impairments is crucial for the prognosis of the subsequent course of $\mathrm{MCl}$ [32].

In the literature, not only the dynamics of progression of impairments are stressed as import- ant, but also the kind of cognitive dysfunctions. In particular, impaired delayed associative memory at baseline can be a potential predictor indicating a high risk of conversion to dementia [7, 33, 34].

However, the problem is that performing a detailed and competent assessment of cognitive functions, due to the time needed for such an examination and the requisite qualifications for an examiner, is often unattainable in practice. Hence the interest in methods that can be widely used, such as the MMSE. However, the role of such simplified methods of measurement should be limited to screening, which should precede the actual full diagnostics, including neuropsychological and neuroimaging diagnostics, and in the future, after better establishing sensitivity and specificity parameters, biochemical specificity.

The current study is not free from a few, quite important, limitations.

Concerns associated with using the MMSE scale as a basis for assessing cognitive function impairments have already been mentioned. One needs to be aware that the MMSE is not a very sensitive measurement tool, and, moreover, it does not allow for precise assessment in separate cognitive areas. However, the goal of the undertaken study was not to assess particular cognitive areas, but to make an overall assessment of cognitive functioning. Additionally, or maybe even most of all, research concerning $\mathrm{MCl}$ was motivated by practical concerns. Tools were used that can be used in everyday clinical work which involves large numbers of patients. While the wide use of MMSE in ambulatory practice is possible, other, more complex, and thus more time-consuming, methods of examining cognitive functions are not suitable for mass use. Despite having used this simplified tool, it was possible to identify differences between individuals converting to dementia and those with a stable course of $\mathrm{MCl}$ as early as during the first year of observations.

Another limitation of the study, which stems from the number of participants under observation, is the failure to take into account the treatment they are undergoing. Though at the time of inclusion in the study the participants did not receive any psychotropic medication, at least some of them $(n=39)$ took such medication in the first year of observation, which is the crucial period for the analysis of our results. The reason for introducing treatment was most often anxiety, decreased mood, sleep disorders, and, in a few cases, aggressive and impulsive behavior.

While the influence of this medication on neurodegenerative mechanisms cannot be ruled out, its potential influence on scores on the MMSE scale, used to assess cognitive functions, is likely to be of more importance. The study was of an 
observational character, which made it impossible to withdraw treatment (if there was such) in the period preceding the assessment of cognitive functions.

Despite the limitations of the methodology of the current research, the results can be useful in making prognoses about the subsequent course of $\mathrm{MCl}$.

An assessment of the intensification of cognitive function impairments, independent of the level of the process, should always lead to further assessment using more sensitive diagnostic methods. Moreover, the occurrence of neuropsychiatric symptoms in an individual exhibiting mild cognitive impairment should be treated as an important element increasing the risk of developing dementia.

\section{Conflict of interest}

The authors declare no conflict of interest.

\section{References}

1. Hanninen T, Hallikainen $M$, Tuomainen $S$, Vanhanen $M$, Soininen $H$. Prevalence of mild cognitive impairment: a population-based study in elderly subjects. Acta Neurolog Scand 2002; 106: 148-57.

2. Petersen RC, Smith GE, Waring SC, Ivnik RJ, Tangalos EG, Kokmen E. Mild cognitive impairment: clinical characterization and outcome. Arch Neurol 1999; 56: 303-8.

3. Wolf $\mathrm{H}$, Grunwald WH, Ecke GM, et al. The prognosis of mild cognitive impairment in the elderly. J Neural Transm Suppl 1998; 54: 31-50.

4. Reisberg B, Ferris SH, de Leon MJ, Crook T. Global Deterioration Scale. Psychopharmacol Bull 1988; 24: 661-3.

5. Forlenza OV, Chiu E. Mild cognitive impairment: a concept ready to move on? Curr Opin Psychiatry 2008; 21: 529-32.

6. Bartres-Faz D, Junque C, Lopez-Alomar A, et al. Neuropsychological and genetic differences between age-associated memory impairment and mild cognitive impairment entities. J Am Ger Soc 2001; 49: 985-92.

7. Yanhong O, Chandra M, Venkatesh D. Mild cognitive impairment in adult: a neuropsychological review. Ann Indian Acad Neurol 2013; 16: 310-8.

8. Rasquin SM, Lodder J, Visser PJ, Lousberg R, Verhey FR. Predictive accuracy of $\mathrm{MCl}$ subtypes for Alzheimer's disease and vascular dementia in subjects with mild cognitive impairment: a 2-year follow-up study. Dement Geriatr Cogn Disord 2005; 19: 113-9.

9. Winblad B, Palmer K, Kivipelto M, et al. Mild cognitive impairment--beyond controversies, towards a consensus: report of the International Working Group on Mild Cognitive Impairment. J Intern Med 2004; 256: 240-6.

10. Petersen RC. Mild cognitive impairment as a diagnostic entity. J Intern Med 2004; 256: 183-94.

11. Taragano FE, Allegri RF, Krupitzki H, et al. Mild behavioral impairment and risk of dementia: a prospective cohort study of 358 patients. J Clin Psychiatry 2009; 70: 584-92.

12. Rosenberg PB, Mielke MM, Appleby B, Oh E, Leoutsakos JM, Lyketsos CG. Neuropsychiatric symptoms in $\mathrm{MCl}$ subtypes: the importance of executive dysfunction. Int J Geriatr Psychiatry 2011; 26: 364-72.
13. Folstein MF, Folstein SE, McHugh PR. Mini-Mental State: A practical method for grading the cognitive state of patients for the clinician. J Psychiatr Res 1975; 12: 189-98.

14. Mungas D, Marshall SC, Weldon W, Haan M, Reed BR. Age and education correction of Mini Mental State Examination for English and Spanish - speaking elderly. Neurology 1996; 46: 700-6.

15. Jóźwiak A, Wiśniewska J, Wieczorkowska-Tobis K. Zaburzenia pamięci $u$ osób starszych oceniane testem Mini Mental Scale. [Memory disorders among elderly individuals assessed on the Mini Mental Scale]. Geront Pol 2000; 8: 46-50.

16. Cummings JL, Mega M, Gray K, Rosenberg-Thompson S, Carusi DA, Gornbein J. The Neuropsychiatric Inventory. Comprehensive assessment of psychology in dementia. Neurology 1994; 44: 2308-14.

17. Yesavage JA, Brink TL, Rose TL, Lum O. Development and validation of a geriatric depression scale: a preliminary report. J Psychiatric Res 1983; 17: 37-49.

18. Diagnostic and Statistical Manual of Mental Disorders, Text Revision (DSM-IV-TR, American Psychiatric Association, American Psychiatric Publishing, 2000.

19. Storandt M, Grant EA, Miller JP, Morris JC. Rates of progression in mild cognitive impairment and early Alzheimer's disease. Neurology 2002; 59: 1034-41.

20. Bidzan I, Nowak M, Cieśla P. Patients with dementia in orthopedic practice. Acta Neuropsychol 2014; 12: 205-13.

21. Migliorelli R, Teson A, Sabe L, Petracchi M, Leiguarda R, Starkstein SE. Prevalence and correlates of dysthymia and major depression among patients with Alzheimer's disease. Am J Psychiatry 1995; 152: 37-44.

22. Modrego PJ, Ferrández J. Depression in patients with mild cognitive impairment increases the risk of developing dementia of Alzheimer type: a prospective cohort study. Arch Neurol 2004; 61: 1290-3.

23. Polyakova M, Sonnabend N, Sander C, et al. Prevalence of minor depression in elderly persons with and without mild cognitive impairment: a systematic review. J Affect Disord 2014; 152-154: 28-38.

24. Katzman R, Kawas C. The epidemiology of dementia and Alzheimer disease. In: Alzheimer Disease. Terry RD, Katzman R, Bick KL (eds). Raven Press, New York 1994; 105-22.

25. Bulboacă AE, Bolboacă SD, Bulboacă AC, Prodan CI. Association between low thyroid-stimulating hormone, posterior cortical atrophy and nitro-oxidative stress in elderly patients with cognitive dysfunction. Arch Med Sci 2017; 13: 1160-7.

26. Berg L, Morris C. Diagnosis Alzheimer disease. In: Alzheimer's Disease. Terry RD, Katzman R, Bick KL (eds). Raven Press Ltd., New York 1994; 9-25.

27. Masur DM, Sliwinski M, Lipton RB, Blau AD, Crystal HA. Neuropsychological prediction of dementia and the absence of dementia in healthy elderly persons. Neurology 1994; 44: 1427-32.

28. Langa KM, Levine DA. The diagnosis and management of mild cognitive impairment: a clinical review. JAMA 2014; 312: 2551-61.

29. Kral VA. Benign senescent forgetfulness. Alzheimer's disease: senile dementia and related disorders. In: Katzman R, Terry RD, Bick KL (eds). Raven Press, New York 1978; 47-51.

30. Luck T, Luppa M, Briel S, Riedel-Heller SG. Incidence of mild cognitive impairment: a systematic review. Dement Geriatr Cogn Disord 2010; 29: 164-75.

31. Wood S, Cummings JL, Hsu MA, Barclay T, Wheatley MV, Yarema KT. The use of the Neuropsychiatric Inventory in 
Nursing Home residents. Am J Geriatr Psychiatry 2000; 8: 75-83.

32. Bidzan L, Bidzan M. Rokowanie w tagodnych zaburzeniach poznawczych. [Prognosis in mild cognitive disorders]. Psychiatr Pol 2004; 38: 251-62.

33. Ying $H$, Jianping $C$, Jianqing $Y$, Shanquan $Z$. Cognitive variations among vascular dementia subtypes caused by small-, large-, or mixed-vessel disease. Arch Med Sci 2016; 12: 747-53.

34. Zając-Lamparska L, Trempała J. Effects of working memory and attentional control training and their transfer onto fluid intelligence in early and late adulthood. Health Psychol Rep 2016; 4: 41-53. 